\title{
Methyl Group
}

National Cancer Institute

\section{Source}

National Cancer Institute. Methyl Group. NCI Thesaurus. Code C93239.

The chemical compound composed of a carbon atom bonded to three hydrogen atoms. 